\title{
Artículos
}

\section{¿Qué modelo económico y qué modelo de sociedad queremos?}

\author{
Departamento de economía
}

\section{1. ¿Hacia dónde nos llevan?}

El anuncio sorpresivo de las nuevas medidas económicas ha generado un desconcierto generalizado en los representantes de las gremiales empresariales y de las asociaciones sindicales y en los diputados de las diversas fracciones políticas. Por lo que toca a las clases populares, simplemente presienten que sobre ellas seguirá cayendo el "derrame" de las nuevas tarifas de luz, agua, teléfono, sumadas a las amenazas del incremento del im- puesto al valor agregado (IVA) y del desempleo (al menos inicial), derivado de los imprecisos proyectos de privatización. Siendo tan diferentes e incluso opuestas en sus intereses, las diversas clases sociales coinciden en la misma pregunta: ¿hacia dónde nos quieren llevar y hacia dónde vamos? Algunos preguntan: ¿qué modelo de sociedad se vislumbra detrás de este agregado de medidas económicas? En el fondo del desconcierto no hay sólo discusiones o divergencias técnicas sobre las medidas económicas, sino serias discrepancias que

* Este artículo ha sido elaborado por los siguientes profesores del Departamento de economía de la Universidad Centroamericana "José Simeón Cañas": Francisco J. Ibisate S.J., Aquiles Montoya, Nicolás Martínez, Carolina Alas de Franco, Rafael Pleitez y Sonia Ivett Sánchez. 
emanan de los sentimientos morales; y más en lo profundo, el temor de que los fríos razonamientos tecnocráticos arrasen los sentimientos y la "cultura" nacionales. Ha sido altamente elocuente que los cuestionamientos, en forma de preguntas y de rechazos, hayan surgido de todas las agrupaciones sociales que explícitamente preguntan, ¿quién está detrás de las bambalinas y quién planifica al planificador?

Ha habido un efecto beneficioso en el sorpresivo anuncio de las nuevas medidas económicas porque ha obligado a hacer una profunda reflexión sobre las posibilidades y debilidades internas del sector productivo para acoplarse a un nuevo modelo económico y algo más importante, sobre las posibilidades y debilidades cívicas y morales que requiere un modelo de sociedad donde no impere la delincuencia organizada y desorganizada, la corrupción generalizada, el tráfico de influencias y la deficiente administración de justicia, agregados integrantes de nuestro "producto nacional", que mantienen un crecimiento superior al 5 por ciento. Ha sido aleccionador que al evaluar nuestras capacidades para transferimos a una nueva modalidad de hacer económico aparezcan estas trabas cívicas y morales que frenan e imposibilitan cualquier renovación económica.

\subsection{Punto de partida: el desconcierto}

De parte del gobierno ha habido una táctica o una pedagogía deficiente en cuanto a la presentación del nuevo modelo económico, no sólo por el elemento sorpresa sino por el objetivo global que buscaría el modelo. Sea o no sea ella la intención final, las cuatro o cinco medidas anunciadas se integrarían en el objetivo final, de reconvertir El Salvador en una colonia o provincia dependiente del mercado internacional (Hong Kong). Expresamente se ha hecho mención de convertir al país en una gran maquila. La supervivencia económica y cierto nacionalismo empresarial lógicamente reaccionan ante la posible supeditación de todos los activos nacionales. Tanto o más arriesgados que los efectos de la privatización aparecen los temores de la desnacionalización. Las clases laborales temen la privatización; los grupos empresariales, la posible desnacionalización. Con ello, el punto cuestionable es que un gobierno arriesgue un proceso de desnacionalización económica y de mayor desarticulación interna de los sectores productivos en aras de los ídolos del mercado, del crecimiento global y de la apertura indiscriminada. Estos temores se fundamentan en las frías recomendaciones de algunos tecnócratas que acuerpan la presentación del nuevo modelo.

En El Salvador no estamos adelantando a reflexionar y discutir en el mes de enero lo que Naciones Unidas propone como temas de reflexión y solución a la próxima cumbre mundial sobre el desarrollo social, que tendrá lugar en Copenhague (Dinamarca) del 6 al 12 de marzo de 1995. El lema inspirador de la cumbre mundial "las sociedades prósperas son las que existen en función del ser humano". Las instituciones de Naciones Unidas y los representantes de los estados miembros se reunirán en la capital de un país desarrollado (Dinamarca) porque, al igual que los países subdesarrollados, todos enfrentan tres grandes problemas: la generalización de la pobreza, el crecimiento sin empleo y la atomización e insolidaridad social (ver Realidad, 1994, 42, p. 841). El mundo enfrenta un problema de crecimiento del subdesarrollo en el interior de sus cuatro mundos, es decir, en todos los modelos económicos.

En los documentos oficiales de nuestros gobiernos y en los informes de los tecnócratas, propiciadores de las nuevas medidas económicas, aparecen los conceptos de crecimiento y de mercado como las premisas fundadoras del bienestar social. La cumbre mundial nos recuerda a todos que codo a codo del mercado y del crecimiento macroeconómico sigue creciendo la pobreza, el desempleo se globaliza y las sociedades se hacen más insolidarias. Uno de los enigmas más claros y demostrados es que nuestro crecimiento es parcialmente ficticio y no emanación del mercado. Monetarizamos las remesas familiares, las llamamos divisas, olvidando que en la pasada y más aún en la presente década, el sacrificio de los emigrantes, los "pobre dólares", es un pilar más fuerte que el cúmulo de las exportaciones para sostener la demanda nacional, el crecimiento interno y la disponibilidad de los medios de pago internacional. El enigma de nuestro crecimiento económico 
es que el sacrificio de los pobres sostiene y refuerza el modelo de mercado, pero el modelo de mercado no sostiene ni refuerza a los pobres. La tasa de crecimiento real, que favorece a unos, se acompaña de una mayor tasa de inflación, que castiga a otros; por lo tanto, hay crecimiento con mayor discriminación de los ingresos, hay crecimiento que está propiciando mayor ostentación de las riquezas en los géneros de vida, hay crecimiento junto con concentración de riqueza y poder. Hay crecimiento real y real crecimiento de la corrupción. Bajo los éxitos macroeconómicos se esconden serias contradicciones sociales que no propician la coexistencia pacífica. Pequeña parcela del mundo actual, donde crece el subdesarrollo, reflexionemos y concertemos las medidas económicas a la luz del lema mundial: "las sociedades prósperas son las que existen en función del ser humano".

\section{2. ¿Hacia una aventura económica?}

Cuando se propone transformar al Banco Central de Reserva en un currency board, en un controlador de la hidraúlica económica (al dinero lo llaman liquidez), aparte de los objetivos y consecuencias económicas que se analizan más adelante, parecería que se echa borrón y cuenta nueva sobre los considerandos que introduce la "Ley Orgánica del Banco Central de Reserva" (abril de 1991), que enfatiza el requisito del ordenamiento. económico. No se comprende fácilmente que el Estado renuncie a una elemental función que aparece en los primeros considerandos de esta ley.

1) Que la Constitución de la República establece que el Estado debe orientar la política monetaria con el fin de promover y mantener las condiciones más favorables para el desarrollo ordenado de la economía nacional.

El capítulo quinto de la misma ley articula "el programa monetario y la coordinación económica (Art. 45). La ley orgánica enfatiza el desarrollo ordenado y la articulación del sector real y monetario, dado el carácter trunco y dependiente de nuestra estructura productiva. Se abandonó razonablemente el monopolio politizado de la antigua Junta Monetaria para hacer del Banco Central de Reserva el banco de la nación, un orientador de la distribución sectorial del crédito productivo, pero ahora se pretendería reducirlo a un simple controlador de la hidráulica cuantitativa, delegando la distribución sectorial al oligopolio concentrado del sistema bancario privatizado. De hecho el sistema bancario está propiciando la peligrosa "terciarización" de nuestra economía (ANEP, Correo Económico, octubre de 1994, p. 2). El ordenamiento económico es uno de los aspectos cuestionables de las medidas económicas propuestas.

Fundamentando el ordenamiento económico estaría el ordenamiento social y regional. Los presidentes centroamericanos, reunidos en Nicaragua (en octubre de 1994), explícitamente lo mencionan y lo prometen al comprometerse por un "desarrollo sostenible", definido como "el proceso de cambio progresivo en la calidad de vida del ser humano, colocándolo como centro y sujeto primordial del desarrollo, por medio del crecimiento económico con equidad social y de la transformación de los métodos de producción y de los patrones de consumo, sustentado en un equilibrio ecológico". Se trata de un compromiso social y centroamericano, basado en siete principios que deben estar presentes en la evaluación de las nuevas medidas económicas: (a) el respeto a la vida en todas sus manifestaciones; (b) el mejoramiento de la calidad de la vida humana; (c) el respeto y aprovechamiento de la vitalidad y diversidad de la tierra de manera sostenible; (d) la promoción de la paz y la democracia como formas básicas de convivencia humana; (e) el respeto a la pluricultura y diversidad étnica de la región; (f) el logro de mayores grados de integración económica entre los países de la región y de éstos con el resto del mundo; (g) la responsabilidad intergeneracional en el desarrollo sostenible" (La Prensa Gráfica, 15 de noviembre de 1994).

\section{¿No será que se pretende hacer de El Salvador un laboratorio experimental de las nuevas medidas, un cobaya económico?}


A falta de mayor explicación es difícil coordinar los objetivos económicos y morales pactados hace cuatro meses en Nicaragua con la intencionalidad última de las medidas económicas propuestas. En el pacto de Nicaragua, al igual que en Copenhague, al menos literalmente, se coloca al ser humano como centro y sujeto primordial del desarrollo. Con nuestras cuatro o cinco medidas no aparece claro que se pretenda revaluar al ser humano o no lo ven así la mayoría de seres humanos. El pacto de Nicaragua habla de agricultura y de pluricultura, lo primero como una vocación de la naturaleza a cambiar y mejorar, y lo segundo como una herencia ancestral que no se debe extraditar. Las pretendidas medidas económicas, así se ha dicho expresamente, convertirían El Salvador en una zona franca. Estas propuestas tecnócratas olvidan que debajo de la agricultura hay una cultura, una pluricultura, rica en valores humanos y espirituales, aunque deformada por la absolutización de la propiedad privada en el agro. Dicha absolutización llevó no sólo a la abolición de los ejidos y las tierras comunales a finales del siglo pasado, sino también a un cambio radical en el uso de la tierra en El Salvador a favor de los productos de exportación y en contra de la producción de alimentos (Browning, El Salvador, la tierra y el hombre, pp. 334-347). Lo anterior ha implicado un constante proceso de empobrecimiento para el campesino salvadoreño. Para los tecnócratas parecería que desaparece el ser humano y se lo transforma en mano de obra. En el pacto de Nicaragua se prioriza la integración económica de los países de la región como un compromiso social. Con las nuevas medidas económicas se propone discutirlas aisladamente y luego ir a exponerlas a los países hermanos. También aquí se presiente un cierto desordenamiento.

En reciente entrevista a Pedro Arriagada, sea o no sea él uno de los inspiradores del modelo, el periodista de La Prensa Gráfica le preguntó "si lo que El Salvador hace es adelantarse a lo inevitable, es como tomar la decisión de abrirse unilateralmente. ¿Dónde quedan los compromisos con Centroamérica? ¿No serían una carga para un proceso de apertura? La respuesta, si bien laudatoria, se presta a varios interrogantes. "Este es un punto muy importante y difícil. El Salvador forma parte del proceso regional, pero sin duda les ha tomado la delantera en sus reformas. Si hoy los demás países no están en la misma línea pasan a ser una carga, y a El Salvador se le hace difícil mantenerse al ritmo de los vecinos. El Salvador, me imagino, se encuentra en un dilema de compromisos a nivel regional versus la maximización de los beneficios locales. Es un punto político que las autoridades tendrán que sopesar y negociar. $\mathrm{Y}$ aunque suene pretencioso decirlo, a este país le tocaría liderar la región para que lo acompañen en este camino" (La Prensa Gráfica, 13 de enero de 1995, p. 16-A).

Respuesta laudatoria, aunque no quede confirmada por la balanza comercial centroamericana. Pero hay algunos interrogantes. El crecimiento hipotético del 8 al 9 por ciento, ¿vale más que los pactos sociales regionales y los aportes económicos progresivos de una integración centroamericana? Otros institutos de investigación ven en la progresiva integración económica un pilar del crecimiento y del desarrollo. Con perdón de la respuesta, en ella se percibe una resonancia del individualismo liberal que vendría a levantar nuevas fronteras sobre las ya existentes. Como preguntar y lanzar hipótesis cuesta poco, ¿no será que se pretende hacer de El Salvador un laboratorio experimental de las nuevas medidas, un cobaya económico?

La hipótesis no es tan veleidosa si seguimos leyendo la entrevista citada. “QQué se hace necesario para asegurar el éxito de este replanteamiento económico? ¿Decisión?”. De alguna manera, la respuesta de Arriaza habla de aventura económica. "El país puede hacer dos cosas: no hacer nada y seguir a un ritmo conservador o acelerar el pedal y pasar a la historia con un éxito o con un fracaso. Ojalá sea con un éxito" (ibidem). La respuesta es un tanto cabalística, porque no deja claro si el experimento puede terminar en un éxito o en un fracaso, o si se identifica el éxito con lanzar el experimento y el fracaso con seguir como estamos. La respuesta es cabalística porque cierra de entrada otras terceras vías. En el pacto de Nicaragua, en la cumbre de Copenhague y en varias propuestas de los institutos de investigación se diseñan sendas humanas para otras terceras vías. Un país, golpea- 


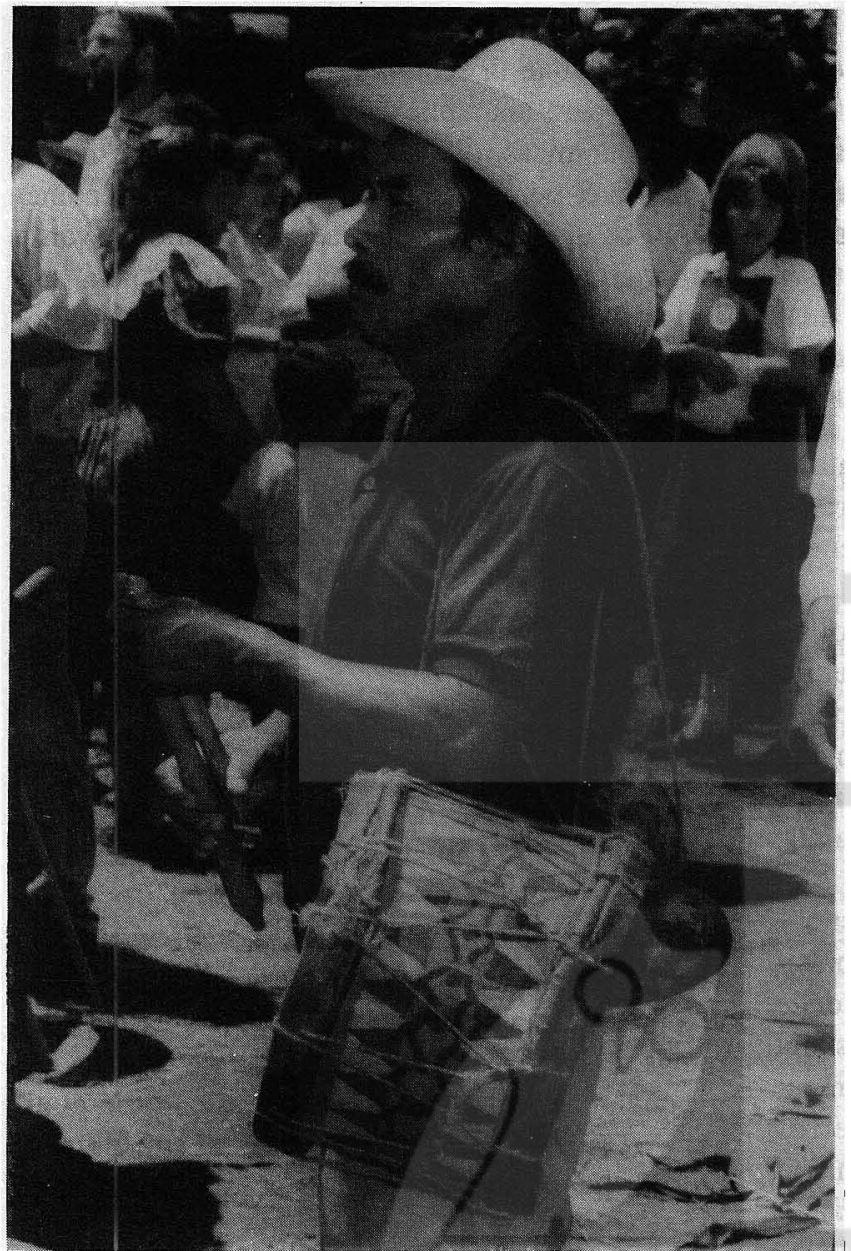

do humana y tecnológicamente por la guerra, económica y socialmente por la pobreza y la discriminación, y políticamente por la corrupción, no puede aventurarse en modelos que simplemente priorizan variables macroeconómicas. Tampoco somos líderes centroamericanos en todos los valores sociales y morales. El redactor de La Prensa Gráfica pone en boca del entrevistado un titular por demás sugestivo, "Gobierno con la espada de Dámocles". El cortesano Dámocles es invitado por el rey Denis a un suculento banquete, pero sobre su cabeza pendía una pesada espada sostenida por un crin de caballo. La alegoría se repite como un símbolo del peligro de la aparente prosperidad. La alegoría es muy acertada si advierte al gobierno de nuestra aparente prosperidad. La alegoría no es del todo completa porque la espada de Dámocles, nuestras medidas económicas, no amenazan primordialmente al gobierno, sino a la mayoría de los gobernados. Volvemos al tema del desconcierto generalizado.

\subsection{Los vaivenes gubernamentales}

El Estado, por Constitución, debe velar por el desarrollo ordenado de la economía nacional; pero el gobierno actual no ha anunciado a la opinión pública un plan de desarrollo económico y sobre todo social, que es lo más económico. A mediados de enero, el presidente Calderón afirma que dicho plan ( $¿$ anual o quinquenal?) está en consulta con los sectores sindicales, empresariales, políticos y militares, "para buscar una concertación" (El Diario de Hoy, 13 de enero de 1995 , p. 2). Los puntos suspensivos siguen porque los consultados dicen no disponer de tal plan y a los no consultados nos cuesta conseguir un ejemplar. Sin que el gran público conozca los objetivos, las áreas prioritarias, las medidas económicas y sociales de dicho plan, no es posible aceptar con fe ciega que el "plan económico beneficiará al país" (ibidem, p. 1). Por gracia o por desgracia ha cundido la desconfianza y los hechos más recientes confirman la pérdida de la credibilidad.

El 13 de octubre de 1994, en El Diario de Hoy se leía un titular que sacudió a la opinión pública, "Proponen nuevo plan de ajuste económico". Un tipo de cambio fijo a diez colones, eliminación de los aranceles, elevación del IVA a cerca del 14 ó 15 por ciento y el establecimiento de un currency board para reemplazar al Banco Central de Reserva en la emisión de moneda (El Diario de Hoy, 12 de octubre de 1994, p. 11 y 13 de octubre de 1994, p. 14). ¿Quién tiró la piedra y movió la mano del redactor? Porque la cablística gubernamental vuelve a actuar. El 14 de octubre de 1994 , el presidente Calderón, quien regresaba impresionado por el pacto de Nicaragua, tranquilizó a la ciudadanía al afirmar que su gabinete "no estudia la posibilidad de adoptar nuevas medidas de ajuste económico... No se ha presentado ningún estudio al comité económico sobre esta situación...". El 
primer mandatario aseguró que "es falso que estemos pensando en subir el IVA, ni cosa que se parezca y esto quiero dejarlo muy claramente establecido... No sea que el día de mañana, a causa de este tipo de informaciones, venga un alza en la canasta básica de este sufrido pueblo. Los pobres son los que en definitiva pagan los platos rotos y una noticia de esta naturaleza golpea en lo más hondo a las clases necesitadas" (ibidem, 12 de octubre de 1994, p. 3).

Tres meses más tarde, el primer mandatario afirma que las mismas medidas son "un aporte al costo de los acuerdos de paz" y vendrían a beneficiar al país, puesto que van a "generar más empleo, bienestar, salud, vivienda y desarrollo" (ibidem, 13 de enero de 1995, p. 2). Esta volubilidad presidencial socava la credibilidad pública, genera más desconcierto y lo único que las mayorías populares deducen es que "los pobres son los que en definitiva pagan los platos rotos". Para que los pobres no paguen los platos rotos, ciertos sectores privados no productivos debieran romper sus propios platos. En su visita a Costa Rica, el presidente Calderón se sintió protegido y respaldado por los comentarios y las recomendaciones del economista Michael E. Porter ("la ventaja competitiva de las naciones"), quien apoyó los esfuerzos para reducir el déficit fiscal y abrir la economía al comercio internacional y a los capitales extranjeros como medidas necesarias, pero no suficientes. El presidente Calderón interpretó estas conclusiones del seminario del INCAE como un espaldarazo a la buena dirección del modelo propuesto por El Salvador. Sin embargo, Porter no solamente dijo eso, sino que también dijo mucho más. Para ello basta leer el capítulo segundo de su obra ( $\mathrm{La}$ ventaja competitiva de las empresas en sectores mundiales y "el papel del gobierno", p. 181) para caer en la cuenta que todas esas medidas no son eficaces sino se incrementa la productividad de los trabajadores, de los empresarios y de la economía en general, integrando la modemización del Estado, cuya misión es influir en los cuatro elementos determinantes de las ventajas competitivas.

La contradictoria realidad que enfrenta el modelo es que las tarifas y los precios se incrementan, pero no así la productividad requerida en muchas de las ramas del sector productivo. Esto demuestra que la economía general no está en capacidad para una aplicación pronta de estas medidas económicas, que se requiere un tiempo de espera. En el tiempo de espera aparecen dos fenómenos. Por una parte, los países del istmo se van a tardar en responder a la propuesta presidencial salvadoreña por la misma razón, pues ni ellos ni nosotros estamos capacitados para dar tal salto cualitativo en un plazo corto. Por la otra parte, "todo parece indicar que los productores y los comerciantes están siendo presa de la especulación y se están cubriendo contra los posibles incrementos del IVA", al igual que en septiembre de 1992. Un modelo que asienta su eje central en el sector productivo privado descubre que tal eje tiene muchas fịsuras y que el Estado no está preparado para impulsar la conversión industrial necesaria. Incluso nos podemos pregunar si el Estado va a mejorar su capacidad para orientar el desarrollo ordenado con las anunciadas transformaciones ministeriales, donde el Ministerio de Planificación y Coordinación Económica Social pasaría a ser un apéndice o una dependencia de otro ministerio. Ahora los dardos presidenciales se enfilan en contra de aquellas ramas de la economía nacional rezagadas tecnológicamente y poco productivas que encarecen el nivel de los precios y sacrifican más al sufrido pueblo. Es interesante que se afirme que la inflación no es sólo inflación por demanda excesiva de algunos, sino por elevados márgenes de ganancia y elevados costos de producción de otros. En estos vaivenes presidenciales hay algunos elementos positivos.

\subsection{Criterios para una reforma}

En algunas de las promesas y enunciados presidenciales hay algunos aportes positivos. El modelo económico no sólo debe ser evaluado por el crecimiento económico conservador del 5 por ciento del PIB, ni su éxito por alcanzar el 9 por ciento, porque estos crecimientos globales no significan todavía ni crecimientos armónicos ni crecimientos con más equidad. Es más atinado evaluar el modelo desde el impacto sobre la calidad del empleo generado, la satisfacción de las necesidades esenciales para la mayoría de los salvadoreños, el nivel de integración del aparato productivo 
nacional, la promoción de las exportaciones articuladas al resto del aparato productivo y cuya competitividad descanse fundamentalmente en increments de la productividad tanto del recurso humano como del capital físico, y la sustitución de las importaciones claves para el funcionamiento del aparato productivo nacional.

Estos criterios deberían inspirar el plan de desarrollo y el quehacer de los sectores público y privado. Según estos criterios, la maquila no puede constituirse en un pilar de desarrollo económico a largo plazo en El Salvador. La maquila genera empleo, pero mal remunerado e incluso en algunos casos no garantiza los derechos de los trabajadores que se encuentran reconocidos en el Código de Trabajo. No ofrece una capacitación que cambie cualitativamente la productividad del trabajador. Más aún, la extensión e intensidad de la jornada de trabajo en la maquila lleva a un desgaste acelerado de la capacidad productiva del trabajador. Un punto más en contra de la maquila es su desarticulación del resto de los sectores de la economía nacional. Por lo tanto, es imperativo diferenciar dos hechos: en la coyuntura actual, la generación de empleo que la maquila ofrece es importante, dadas las altas tasas de desempleo existentes y esto no implica que el desarrollo futuro de El Salvador se logre convirtiéndose en una gran zona franca maquiladora por las razones ya dichas.

De acuerdo a la dirección de los nuevos vientos se busca transferir algunas funciones productoras y ejecutoras del sector público al sector privado, dicen que buscando el bien de los consumidores; pero hay una función que no debe abandonar el Estado, la de orientar, promover e impulsar el crecimiento armónico, el crecimiento con equidad y el desarrollo social.

\subsubsection{Orientaciones cuantitativas}

Por lo que toca al crecimiento armónico directamente y al crecimiento con equidad más indirectamente, es de agradecer al Banco Central de Reserva la publicación de las matrices intersectoriales de 1978 (en 1986), de 1990 (en 1993) y la actual preparación de las matrices de 1991, 1992 y 1993. Este valioso informe de la contabilidad nos revela la estructura interna productiva con sus logros, sus lagunas, sus desviaciones (terciarización) y sus potencialidades. Este es un aporte positivo al análisis estructural, a la planificación ordenada de la economía nacional y regional, y a las recomendaciones de $\mathrm{M}$. Porter en orden a descubrir qué sectores cuentan y qué sectores no cuentan con ventajas competitivas relativas en el ajedrez internacional. Por ello, no creemos que el Banco Central de Reserva deba reducirse a un simple currency board, controlador de la emisión global de dinero, en función de las divisas disponibles. El crecimiento armónico y equitativo requiere un ordenamiento del multiplicador del crédito y del multiplicador de la inversión hacia los sectores dinamizantes como oferentes y demandantes de otras ramas productivas. A este propósito cabe advertir que los análisis de las matrices insumo-producto de 1978 y 1990 revelan que, por gracia del mercado, bastantes de estos sectores claves se hallan concentrados en formas de propiedad mono y oligopólicas (el caso típico es el actual sistema bancario), que esconden el lado oscuro de las recomendadas privatizaciones de los activos públi$\cos$.

Muy en relación con los interrogantes que, a nivel nacional y regional, plantean las nuevas medidas económicas hay —entre otros - tres aspectos que estas matrices intersectoriales nos revelan. En primer lugar, la falta de integración económica interna, la falta de encadenamientos productivos entre lo que suele llamarse el sector primario (extracción, agropecuario, pesca...) y el sector secundario de la industria manufactura. Para el crecimiento armónico tanto o más importante que el énfasis en la maquila (sector final) es la constitución ordenada de las ramas agro-industriales. El concepto agro-industrial es importante por una segunda revelación que nos hacen estas matrices. $\mathrm{El}$ quehacer económico se realiza sobre una superficie espacial o sobre geografía concretas, que indirectamente salen a relucir en las actuales discusiones. El Salvador, siendo un país pequeño superficialmente, son dos El Salvador: el urbano, donde tienden a concentrarse los servicios privados y públicos y también la población, y el agro salvadoreño, desposeído de servicios privados y públicos. El agro ha sido el generador del ahorro (las divi- 


\section{Para abrirse hacia fuera, nuestra economía necesita una mayor integración, diversificación y modernización internas.}

sas) y de las fuentes de energía, pero está desprovisto de energía, de la infraestructura física y social que financiarían aquellas divisas y donde lógicamente no se plantea el problema de la privatización de activos rentables. La ausencia de crecimiento armónico geográfico ha ido profundizando la falta del crecimiento equitativo geográfico.

Esta desolación agraria explica las migraciones continuas de población hacia las áreas urbanas y hacia la emigración extranacional. La "transformación en la estructura agraria de El Salvador" (Realidad, 1994 41, p. 699) explica la preocupación de que las nuevas medidas económicas arrasen este amplio sector y, por lo tanto, la necesidad de redimirlo y de reestructurarlo.

Hay un tercer problema que sobriamente nos revelan los análisis de estas matrices intersectoriales: la estructura de la demanda deficiente. El análisis secuencial de las componentes del valor agregado o de las remuneraciones factoriales muestra que los montos del excedente de producción bruta vienen creciendo en mayor proporción que las remuneraciones laborales, la reposición de capital y los impuestos indirectos. Sin duda, esta discriminación de los ingresos factoriales puede explicar el fenómeno de la "terciarización" de los sectores productivos, siendo así que las mismas matrices revelan que "la satisfacción de las necesidades básicas integran ramas reactivantes de la economía nacional" (Boletín de Ciencias Económicas y Sociales, julio-agosto de 1987, p. 226).

Estas reflexiones, bajo la forma de interrogantes o de cuestionamientos, están aflorando en las discusiones de las nuevas medidas económicas. El Banco Central de Reserva ha creado y ha puesto a disposición de la administración pública, del sector privado y especialmente del Ministerio de Planificación un documento contable, un radar orientador del nuevo plan de desarrollo y un radar evaluador de las medidas económicas propuestas. Para abrirse hacia fuera, nuestra economía necesita una mayor integración, diversificación y modernización internas. Ignoramos si la administración pública está haciendo uso de este producto. Pare- ciera que el mismo Banco Central de Reserva no le ha dado la requerida publicidad.

El desconcierto y la divergencia de opiniones en los sectores empresariales y laborales frente a las medidas anunciadas pone de manifiesto que el "mercado" no es una unidad homogénea de productores, sino un conjunto heterogéneo de ramas productivas que, aunque interrelacionadas, se sienten desigualmente afectadas, beneficiadas o dañadas, por cada una de las medidas económicas. Es claro que tendríamos efectos muy discriminantes si el tipo de cambio se fijara en 8.50, 8.75 ó 10 colones por dolar. Las tres hipótesis podrían tener sus respectivos defensores, al igual que crece la tesis de que no conviene y no podemos mantener un cambio fijo en el mediano plazo. Es claro que la reducción y la eliminación de los aranceles favorecería momentáneamente a algunas ramas productivas, mientras que expulsaría de la escena económica a otros sectores importantes. Pensemos, a manera de ejemplo, en los productores de granos básicos. Si se eliminan los aranceles para estos productos, nuestros campesinos enfrentarán una competencia desleal, dado los altos niveles de subsidio con los que cuentan los productores de Estados Unidos y de otros países. Y sería un irrespeto cultural y una idea disparatada creer que de la noche a la mañana nuestros campesinos pueden convertirse en obreros de maquiladoras. Nuestros gobernantes no debieran ignorar que el 54 por ciento de la población económicamente activa en el sector agropecuario, que asciende a 581,661 personas aproximadamente, lo constituyen minifundistas con una manzana o menos de tierra, desempleados y trabajadores temporales, cuyos ingresos se encuentran muy por debajo del promedio nacional (Realidad, 1994, 41, pp. 711 y 733).

La vida de este grupo de compatriotas depende primordialmente de la reactivación de nuestra agricultura y de la capacidad que tengamos para fomentar la agro-industria. Se necesitan medidas urgentes para fomentar sus actividades productivas; lo último que necesitamos son medidas económicas que las dificulten todavía más. La situa- 
ción del agro es grave. Una medida tan aventurada como una apertura comercial total podría ser un atentado para la estabilidad social y política, la cual es un prerrequisito para cualquier estrategia de desarrollo sostenible. Es claro que el incremento del IVA favorecería al Ministerio de Hacienda y a las empresas que lo cobran y no lo pagan, pero castigaría sobradamente a la mayoría de la población. Esta medida ofende la equidad. Es claro que determinadas privatizaciones beneficiarían lucrativamente a determinadas empresas y a ciertos consumidores, pero generarían la angustia del desempleo en amplios sectores laborales. Este mercado tan heterogéneo y falto de poderes compensadores no puede, por sí sólo, ser el eje orientador del quehacer económico. Adicionalmente, las intervenciones sucesivas en los medios de comunicación social nos revelan un conjunto de fenómenos nacionales que dificultan el paso del crecimiento global hacia el desarrollo social.

\subsubsection{Orientaciones cualitativas: el producto nacional implícito}

Este concepto es poco usual, pero quiere significar algo muy real y cierto. Entendemos por producto nacional implícito un conjunto de hechos y circunstancias de difícil cuantificación monetaria, que afecta directamente al producto monetizado de la contabilidad nacional y que, por añadidura, hay que integrar al analizar la viabilidad de las medidas económicas propuestas o de cualesquiera otras medidas. Se trata de hechos y circunstancias producidos o dejados de producir dentro del país. En este sentido, producto nacional implícito es la menor productividad y competitividad de bastantes sectores económicos que temen la apertura internacional. Lo es también la falta tradicional de integración económica interna en razón de la estructura oligoexportadora tradicional. Producto nacional implícito es la notoria ausencia de cualificación profesional de la mano de obra, por culpa de muchos y que resulta premisa requerida en las recomendaciones del M. Porter. Producto nacional implícito es que se requiera una ley y una comisión de ciencia y tecnología para que, desde las universidades, desde el sector privado hasta el sector público, comprendamos que no hay tecnología sin investigación y sin inversión. Producto nacional implícito es que nos rasguemos las vestiduras ante el Decreto 187 del estado californiano, pero lo vengamos practicando sin decreto en el país desde hace décadas.

Producto nacional implícito es la corrupción generalizada, la triste y desorganizada delincuencia callejera, inspirada en la gran delincuencia organizada del narcotráfico, el lavado de dólares, el carro-tráfico, el crimen civil o político, la gran mordida, el tráfico de influencias, la aún deficiente administración de justicia, el ocultamiento de la verdad, tantas inseguridades sociales que, mientras frenan la inversión nacional, levantan los mayores aranceles a la llegada de la inversión extranjera.

Producto nacional implícito es el miedo, la inseguridad en que vivimos todos, así como la insolidaridad social de postguerra que se manifiesta hasta en el resquebrajamiento de los partidos políticos. Y de manera especial, producto nacional implícito es la creciente pobreza relativa, que no solucionamos ni el sector público ni el privado. Producto nacional implícito es que el gobierno esté más interesado en privatizar los activos del sector público que en privatizar. los activos concentrados del sector privado, y que las políticas fiscales y crediticias avancen en esa dirección. Se pueden integrar otras componentes adversas de este producto nacional implícito tan real como difícil de monetizar.

Contamos con suficientes instrumentos y análisis de la contabilidad nacional como para orientarnos hacia un mayor crecimiento armónico. Contamos con la experiencia de que puede darse y de hecho ya se está dando un crecimiento global sin equidad, discriminante y "terciarizado", que no fundamenta el desarrollo sostenible. Contamos con programas alternativos de varios institutos de investigación en lo que se refiere a propuestas técnicas. Instituciones internacionales reclaman la reforma social que potencie la reforma económica, la equidad con la transformación productiva $y$, más cerca de nosotros, los objetivos del pacto de Nicaragua. Por lo que atañe al desarrollo social, tal como se repetirá en la próxima cumbre de Copenhague, es una tarea de todas las fuerzas so- 
ciales. Por este desarrollo social se libró una guerra. Quisiéramos que el gobierno actual y sus gobernadores, así como todos nosotros, actores del sector privado, nos inspirásemos hoy y mañana en ese lema: "las sociedades prósperas son las que existen en función del ser humano".

\section{Análisis de las medidas económicas pro- puestas}

Teniendo en consideración las orientaciones cuantitativas y cualitativas abordadas anteriormente, a continuación analizamos el conjunto de medidas económicas propuestas recientemente por el gobierno.

\subsection{El aumento del IVA}

El aumento de dos puntos porcentuales de la tasa del Impuesto al Valor Agregado (IVA) que el gobierno propone llevar a cabo, es una medida de política tributaria que pretende corregir el problema del déficit fiscal. Pero las causas de este déficit a menudo son obviadas y no son tomadas en cuenta a la hora de proponer soluciones al problema. Por lo tanto, es necesario analizar las distintas implicaciones del incremento en la tasa del $\Gamma^{\top} \mathrm{A}$ en el contexto fiscal salvadoreño.

La conveniencia económica para incrementar la tasa del IVA debe evaluarse, en primer lugar, partiendo de su eficiencia micro y macroeconómi$c a$. Un mayor IVA no genera un cambio cuantitativo importante en la estructura de los precios relativos de las distintas ramas de la economía, por lo cual dicho incremento es microeconómicamente eficiente. A nivel macroeconómico, se espera que un mayor nivel de la tasa contribuya a aumentar el ahorro público (o a disminuir el desahorro, el cual se refleja en la existencia del déficit fiscal). Obviamente, un desahorro menor del sector público provocado por un IVA mayor tiene como contrapartida un castigo para el consumo privado. Además, si bien teóricamente un mayor nivel del IVA no tiene por qué causar un mayor nivel de inflación, sí implica un mayor nivel de los precios en la economía y una reducción de la capacidad de compra de los consumidores, lo cual es indeseable en el contexto de depresión acumulada del poder de compra de muchos contribuyentes.
Esto último se agrava por la presencia de dos características económico institucionales de la economía salvadoreña. Primera, los salarios y las pensiones nominales de los trabajadores, los pensionados y los jubilados, no están indexados con la inflación pasada y mucho menos con la esperada; por lo tanto, los salarios y las pensiones no se ajustan ante mayores niveles de precios o de inflación. Segunda, las expectativas de muchos empresarios son bastante inflacionarias, provocando aumentos de los precios aun antes de que las medidas anunciadas entren en efecto. Ambas características tienden a discriminar el impacto de un mayor nivel de las tasa del IVA sobre un tipo específico de consumidor final: el asalariado, el pensionado, el jubilado o, en definitiva, el no empresario, ya que éste último puede perfectamente reajustar sus ingresos ajustando el precio de su producción (bienes o servicios), incluso en una proporción mayor al del incremento del impuesto.

En segundo lugar, el análisis del impacto de un mayor impuesto requiere considerar el esfuerzo tributario dinámico en que han incurrido los distintos tipos de contribuyentes del sistema tributario. En El Salvador, el pago de impuestos de los contribuyentes totales ha crecido en forma constante, habiéndose pasado de una recaudación equivalente al 7.6 por ciento del PIB en 1989 hasta alrededor del 9.7 por ciento en 1994. Esta mayor recaudación significa que los contribuyentes han tenido que sacrificar consumo privado para poder aumentar su contribución tributaria. Pero no todos se han esforzado en la misma proporción, ya que en el período 1989-1993, los impuestos recaudados en forma indirecta, vía tasación del consumo final, han crecido a una tasa anual que es 8.4 puntos porcentuales mayor que el crecimiento de los impuestos recaudados con la tasación sobre la renta y el patrimonio de las personas jurídicas y naturales.

Esta diferencia en el esfuerzo tributario intertemporal implica que, a pesar de la mayor carga tributaria, el consumo privado real no ha disminuido en términos absolutos. En el período 1989-1993 presenta una tasa de crecimiento promedio anual del 2.6 por ciento. Obviamente, que el consumo privado real no se ajuste a un nivel 
mayor de impuestos indirectos, no se debe a que los consumidores promedio hayan tenido un mayor ingreso real. Al contrario, se sabe que en el último quinquenio, los salarios nominales anuales han crecido en menor proporción al crecimiento de los precios, generando una reducción de la capacidad adquisitiva de los consumidores asalariados, pensionados y jubilados. Por lo tanto, este sector tuvo que ajustar su consumo real ante mayores impuestos. Por otro lado, los contribuyentes directos, principalmente los de ingresos altos y los poseedores de patrimonio con mayor valor, fueron incentivados a no disminuir su consumo, al ser beneficiados con las reformas tributarias del último lustro.

Lo anterior se evidencia porque las reformas 'a la tabla de impuestos sobre la renta de las personas naturales, realizadas en 1989 y 1991, contenían una reducción significativa de los impuestos que tenían que pagar quienes percibían los ingresos más altos, ya que a mayor ingreso se decretó una mayor reducción del impuesto vigente en 1989. En el caso de las personas jurídicas, las reformas de 1989 y de 1993 también estipularon reducciones mayores para las rentas más altas. En 1994, se abolió el impuesto al patrimonio.

En este contexto de esfuerzo tributario diferenciado - y económicamente inequitativo- un mayor nivel de la tasa del IVA solamente producirá mayor regresividad en el sistema tributario y no asegura un estímulo importante para el ahorro interno, limitando la pretendida eficiencia macroeconómica del impuesto.

En tercer lugar, el aumentar el IVA del 10 al 12 por ciento significa un incremento cuantitativo de dos puntos porcentuales, el cual tiene un impacto deseable o indeseable, dependiendo del tipo de estructura impositiva en la cual se dé el incremento del impuesto.

En El Salvador, a partir de 1991, la estructura tributaria ha tendido (producto de la reforma tributaria del gobierno de Cristiani) a profundizar su tradicional carácter regresivo, ya que la participación de los impuestos directos ha disminuido y la de los impuestos indirectos (al consumo final, los que iricluyen el IVA) ha aumentado. Por lo tanto, el incremento propuesto de la tasa del IVA seguramente provocará que más del 75 por ciento de los ingresos tributarios se recauden con impuestos indirectos. Ello tiene carácter regresivo evidente, pues tasa el consumo independientemente del nivel de ingreso de quien paga el impuesto. Este incremento es, obviamente, indeseable desde una perspectiva de equidad económica y social. Si la mayor parte de los impuestos proviniera del impuesto a la renta y al patrimonio, un incremento del IVA tendría carácter "equilibrador", pero éste no es el caso, dado el contexto tributario vigente.

En cuarto lugar, desde que se implantó el IVA (1992), su importancia relativa asciende entre el 45 y el 50 por ciento del total de los impuestos recaudados. La tasa del 10 por ciento aplicada actualmente no es pequeña. Sin embargo, la eficiencia administrativa del gobierno en la recaudación del impuesto es pésima, ya que se calcula que solamente se recauda alrededor del 50 por ciento de la recaudación potencial. Por lo tanto, económica

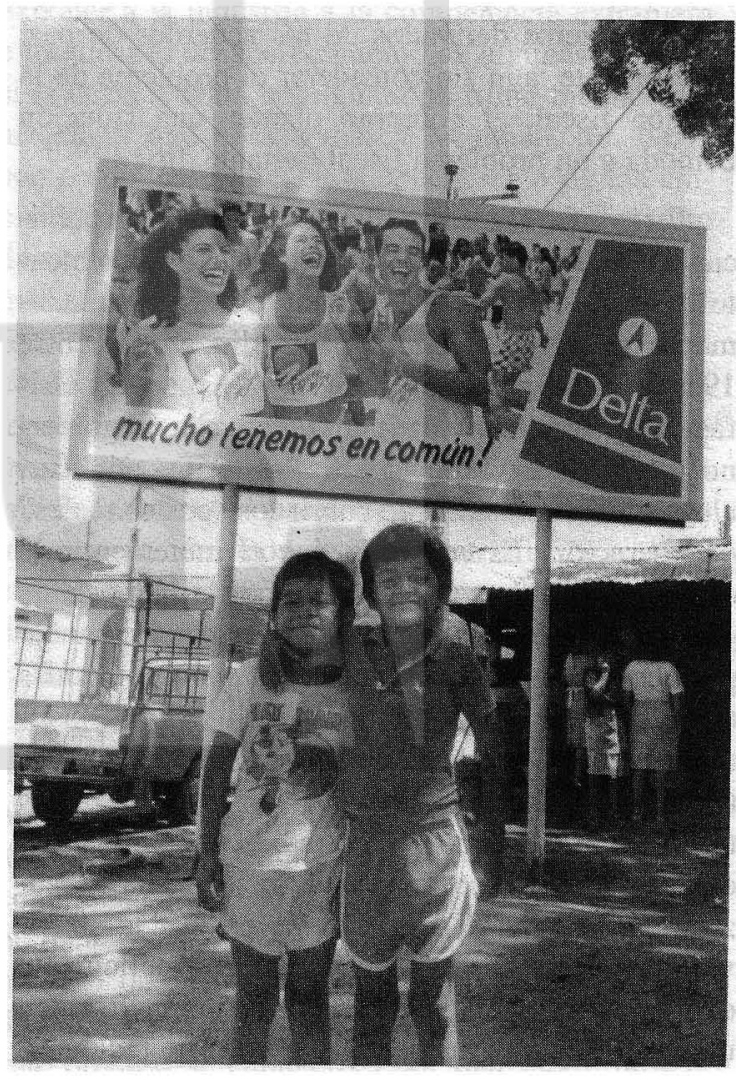


y socialmente es mucho más deseable aumentar la eficiencia administrativa del Ministerio de $\mathrm{Ha}$ cienda que aumentar la tasa del IVA al 12 por ciento, principalmente por dos razones. La primera, el IVA difícilmente es evadido por el consumidor asalariado, pensionado y jubilado, ya que el consumidor final siempre paga el impuesto. El aumento de la eficiencia no afectaría a este sector de ingresos bajos. Segunda, la evasión fiscal está identificada con las operaciones de muchas empresas medianas y grandes. Por lo tanto, si este sector no evadiese el IVA, permitiría un aumento de la carga tributaria del país en casi el 50 por ciento, posibilitando cerrar el déficit fiscal.

Además cle estos cuatro aspectos que permiten una evaluación del impacto del incremento propuesto al IVA, conviene valorar la justificación oficial para decretar dicho incremento. En sus declaraciones, los funcionarios públicos y el mismo presidente de la república plantean el aumento de la tasa del IVA como una necesidad para financiar el déficit fiscal, profundizado por los compromisos financieros derivados de los acuerdos de paz. Nuevamente, aún sin considerar el problema de la evasión fiscal, el gobierno plantea una solución cómoda a un problema fiscal bastante difícil.

En primer lugar, casi todas las empresas públicas continúan teniendo déficits a pesar del aumento de sus ingresos de operación en aproximadamente el 21 por ciento, promedio anual, entre 1993 y 1994, producto del cobro de mayores tarifas de agua, electricidad, teléfonos, etc. El gobierno justifica esos aumentos de las tarifas públicas, alegando la necesidad de cubrir los "costos reales" de operación. Es conocido que el incremento de esos costos reales es producido por la ineficiencia gerencial de las empresas, causada por el manejo político a que históricamente han sido sometidas (recuérdese que esas empresas incluso han constituido lugares de "destierro" para políticos corruptos o "purgados"). Por lo tanto, un aumento en las tarifas públicas debe ser precedida por un análisis exhaustivo del costo marginal "real" de largo plazo que se pretende cubrir, para verificar la efectividad real del costo. Seguramente, el déficit real que debe ser financiado tendría que reducirse con una política gubernamental de autodepuración fi- nanciero administrativa.

En segundo lugar, no es correcto justificar el incremento de la tasa del IVA alegando el costo de la paz, ya que, en el último quinquenio, los consumidores asalariados y de bajos ingresos fueron los más perjudicados con la reforma tributaria; luego, los costos de la guerra fueron pagados con vidas e ingresos principalmente provenientes de esos sectores de ingresos bajos. Se sabe que si alguien se benefició financieramente de la guerra, ése no ha sido el sector de bajos ingresos. Consecuentemente, este intento de justificar el alza del IVA lo único que evidencia es la enorme desarticulación existente entre el manejo de la política fiscal y la implementación de la política social del gobierno (si es que existe una política social definida con precisión).

En tercer lugar, la existencia del déficit, producto de la evasión y la corrupción, de la ineficiencia administrativa del Ministerio de $\mathrm{Ha}$ cienda y de las empresas públicas, no debiera ser financiado con un mayor nivel del IVA. Si el déficit fiscal es preocupante, por las implicaciones macroeconómicas que conlleva, entonces, ese desequilibrio debe ser visto desde la perspectiva del sector público consolidado (el cual incluye al Banco Central de Reserva y a la banca de desarrollo). Esto debe ser visto así, porque para el equilibrio del ahorro y la inversión, lo que interesa es el ahorro interno global. Se sabe que en los últimos dos años, el ahorro interno promedió el 2.4 por ciento del PIB, en tanto que la inversión interna promedió el 16.7 por ciento. Este desequilibrio es mayor si se observa que el ahorro público nacional apenas promedió el 1 por ciento del PIB. Pretender subir ese ahorro público elevando la tasa del IVA, tiene una implicación macroeconómica distinta a la que se diera si el aumento del ahorro público lo produjera una verdadera racionalización del gasto público. En este sentido, incluso las pérdidas que el Banco Central de Reserva tiene por el manejo contradictorio de sus políticas monetaria y cambiaria tendrían que pasar una prueba de racionalidad económica y social. Por lo demás, es obvia la indeseabilidad económico financiera de cerrar un déficit global vía un mayor ahorro público a costa de un menor consumo y ahorro privado. 


\subsection{La reducción arancelaria propuesta}

El reciente anuncio sobre el descenso en las tasas arancelarias hasta llegar progresivamente a su total eliminación, más que una nueva medida, es una continuación de la desgravación arancelaria que comenzó el gobierno del presidente Cristiani, con la diferencia que ahora se pone como meta la eliminación indiscriminada y completa de los aranceles en un periodo de dos años y medio. En efecto, el gobierno anterior bajó el techo máximo del 290 hasta el 20 por ciento, y elevó el piso de 0 al 5 por ciento, salvo ciertas excepciones tales como algunas prendas de vestir y bienes suntuarios. Al mismo tiempo, redujo el número de tramos entre el límite superior y el inferior.

La desgravación no fue muy bien aceptada por los productores de bienes sustitutos de importaciones, por cuanto marcaba un cambio radical en el antiguo modelo de sustitución de importaciones. El aparato industrial había crecido bajo la sombrilla de la necesidad de proteger la industria naciente por medio de altos aranceles para los bienes de consumo final y aranceles mucho más bajos para los insumos, los bienes intermedios y la maquinaria. Esta estructura arancelaria debía proteger a la industria incipiente hasta que ésta estuviera en condiciones para competir con la industria de los países más desarrollados, que producían con mayor eficiencia y con economías de escala que les permitían abastecer un mercado más grande que nuestro mercado local, incluso más grande que el mercado centroamericano.

La protección arancelaria se extendió por varios años, desvirtuándose el objetivo para el cual había sido implementada inicialmente. De esta forma, se convirtió en un medio para favorecer, sobretodo, a un pequeño grupo de industriales que logró generar altas tasas de ganancia, a pesar de la ineficiencia con que operaba. Este fue el razonamiento que justificó la reducción de los aranceles, la cual se veía como una medida impostergable si se considera que la globalización de la economía requería que el país contara con una industria altamente competitiva a nivel mundial que le permitiera penetrar nuevos mercados.

Paralelamente se mencionaba la necesidad de la reconversión industrial, con todo lo que ello implicaba: modernización, capacitación, innovación tecnológica, infraestructura adecuada, control de calidad, mayor agresividad en la penetración de nuevos mercados, etc., además, el gobierno dio mayor énfasis a la política de promoción de las exportaciones.

En ese contexto, se avanzó en la desgravación arancelaria, pero no en la implantación de políticas y medidas, en las cuales participaran tanto el Estado como el sector empresarial para apoyar la reconversión industrial. Analicemos los posibles beneficios y costos de la reducción arancelaria propuesta.

En primer lugar, es obvio que la desgravación por sí sola no implica necesariamente una reconversión rápida y adecuada de la industria nacional, sino que, paradójicamente, puede significar, dependiendo del ritmo al que se lleve a cabo y a los niveles a que se llegue, el desaparecimiento de la industria. Una baja de los aranceles puede exponer a la industria a la competencia extranjera e implicar el desaparecimiento de algunas de ellas, si la desgravación continúa a un ritmo mucho más acelerado que el que marca la generación de la competitividad. Si el desaparecimiento de las empresas no es contrarrestado con el establecimiento de otras nuevas, nacionales o extranjeras, estaríamos ante una creciente población desempleada. Este mayor desempleo reflejaría el deterioro de las condiciones de vida de las mayorías. Por lo tanto, la desgravación arancelaria puede generar, contrario a lo que se ha dicho, un debilitamiento serio de los sectores productivos. Lo que costó años levantar en términos de la industrialización de la economía y creación del aparato productivo, puede desaparecer en un período de tiempo bastante rápido.

En segundo lugar, se ha pretendido justificar la eliminación completa de los aranceles invocando el ejemplo de la industrialización de los países asiáticos. Sin embargo, deben considerarse las condiciones históricas, culturales, políticas y económicas en las cuales estos países iniciaron su proceso de industrialización y el escenario mundial que prevalecía en ese entonces. En sus inicios, este proceso se caracterizó por una fuerte protec- 
ción selectiva y gradual de la industria por medio de aranceles, junto con metas de producción y exportación y gratificación a las empresas que lograran cumplirlas, así como una elevada protección a la agricultura. En cada etapa se trató de mantener aquellas industrias consideradas como estratégicas al mismo tiempo que se eliminaban los aranceles de los insumos. Estas medidas eran acordadas conjuntamente entre el gobierno y el sector empresarial, y eran acordes a los objetivos estratégicos de largo plazo, previamente establecidos, y para los cuales se formulaban planes en forma concertada, dentro de los cuales la política sectorial referente a la industria tenía un papel relevante.

Adicionalmente, la desgravación arancelaria supone que ya se ha tomado en cuenta el desarrollo económico desigual de los países con los que se comercia y con aquellos con los que se puede iniciar alguna actividad comercial. En este sentido, que logremos penetrar nuevos mercados no depende de una apertura unilateral de nuestra economía, sino más bien de incrementos de competitividad real interna y de aspectos complementarios importantes.

Puesto que existe una desigualdad bastante grande entre nuestra industria y la de los países más avanzados, nada indica que no pueda implementarse una protección sectorial selectiva de aquellas industrias con potencial para expandirse y exportar, sin que esto signifique elevar las tarifas arancelarias. Una política sectorial para la industria debería incluir planes de modemización, mejora de la infraestructura, suministro de servicios básicos, incorporación de nueva tecnología, adiestramiento de personal, centros de información de oportunidades en el exterior, entre otros.

En tercer lugar, la eliminación de los aranceles tiene implicaciones en los ingresos tributarios del gobierno. Aunque la imposición de los aranceles constituye una política comercial ligada sobre todo a resolver los problemas del sector externo, indudablemente para efectos prácticos, una vez implementados, los aranceles se convierten en un ingreso para el fisco, por lo tanto, no se pueden eliminar sin considerar fuentes alternas de ingresos o al menos no sin analizar las repercusiones que su supresión tendría en el déficit fiscal.
Por otro lado, no se ha justificado apropiadamente por qué es necesaria la eliminación total de los aranceles para volvernos realmente competitivos. Aun aceptando que una reducción gradual de los aranceles, junto con una reconversión de la industria son requisitos para poder ganar competitividad, esto no quiere decir que aquéllos deban eliminarse completamente. Para apoyar la moción de cero aranceles se tendría que aceptar como un hecho que todas las ramas industriales se encuentran, en el momento de su eliminación, en condiciones para competir en el exterior o que la "mano invisible" de la economía se encargará de decir qué ramas merecen sobrevivir y cuáles no.

Además, existen muchos bienes considerados de consumo suntuario que podrían continuar siendo gravados. Así, se conservaría una fuente de ingresos sin que el grueso de la población fuera afectada, ya que, por sus niveles de ingreso, esos productos no forman parte de su canasta de consumo y, al mismo tiempo, estos aranceles tampoco afectarían a la industria nacional por ser bienes que generalmente no son producidos internamente.

La reducción de los aranceles para los insumos, los bienes intermedios y la maquinaria, obviamente, significará una rebaja en los costos de producción de los empresarios, pero no debemos olvidar que si algunos bienes considerados como insumos para algunas empresas son a la vez producidos internamente, como es el caso del papel, la reducción de los aranceles a los insumos debilitará una parte del aparato industrial. En ese sentido, debemos ver el costo contra la ganancia generada por la reducción de los costos de producción de la mayoría de las empresas.

La eliminación completa de los aranceles, por otro lado, significaría que las negociaciones de acuerdos de libre comercio y las negociaciones sobre aranceles en el marco de la integración centroamericana carecen de sentido, en la parte de desgravación arancelaria. Además, sería una desviación del objetivo de formar bloques económicos, que es la tendencia actual encabezada por las grandes potencias. Si bien las negociaciones en torno a áreas como barreras no arancelarias, servicios, inversión, medidas de salvaguardia, compe- 
tencia desleal y otras podrían continuar, mucho del reducido poder de negociación que tenemos ante países económicamente más fuertes, se perdería.

En las negociaciones sobre acuerdos de libre comercio que se han dado hasta ahora, una de las estrategias de negociación ha sido que antes de comenzar formalmente dichas negociaciones, algunos países han elevado sus aranceles o han endurecido sus barreras no arancelarias, ya sea introduciendo nuevas medidas o exigiendo con mayor rigurosidad requisitos que en la práctica no habían estado siendo aplicados. De esta manera, esos países adquieren un margen más amplio de negociación para lograr concesiones adicionales a cambio de la respectiva eliminación de estas barreras.

El desaparecimiento de los aranceles nos pondría en una situación en la que se renunciaría a la concesión que países más grandes han hecho, aunque no siempre cumplido, en las negociaciones de libre comercio se contempla la desigualdad de las economías. Este reconocimiento permite que los países menos desarrollados puedan llevar a cabo una desgravación más lenta y con un mayor número de sectores protegidos temporalmente. Al negociar el reciente tratado de libre comercio entre Estados Unidos, Canadá y México, los tres países convinieron en una desgravación gradual hasta un máximo de diez años, incluyendo una serie de sectores o productos considerados como sensibles, los cuales gozarían de una protección mayor y con plazos de desgravación de hasta quince años. En esta negociación, México ha obtenido las concesiones mayores. De por sí, el tratado es un documento complejo que toma en cuenta las características diferentes a un nivel bastante desglosado de la industria, así como también establece una serie de mecanismos de salvaguarda y para solucionar las controversias, y medidas antidumping, fito-zoo sanitarias, para proteger el medio ambiente, de seguridad nacional, de bienes culturales, etc.

Cabe preguntarse, entonces, si la negociación tan prolongada del tratado de libre comercio fue completamente innecesaria, puesto que el camino mejor habría sido eliminar completamente los aranceles al mismo ritmo en los tres países y en un plazo mucho menor. O será que las condiciones particulares de nuestra economía hacen que se necesite únicamente de un período de dos años y medio para lograr la reconversión industrial en los sectores con potencial y la penetración exitosa al mercado mundial, sin conflictos y sin sufrir las consecuencias de medidas desleales que puedan adoptar nuestros socios comerciales actuales o futuros. La experiencia reciente de México parece apuntar al hecho que, por muy bonancible que pueda parecer una economía en un momento dado, ello no saca a un país de su condición de subdesartollo, y la desgravación arancelaria, si no va. acompañada de otras medidas como una política sectorial industrial de modernización, una disciplina fiscal y un sector externo estable, puede debilitar seriamente la base de la industria y llevar a una crisis económica seria en corto tiempo.

$\mathrm{Si}$ partimos que en El Salvador ya se inició un proceso de desgravación arancelaria importante y que, al mismo tiempo, la productividad de las empresas nacionales está muy por debajo de la productividad existente en los países más avanzados, se debe ser muy cauteloso en los próximos pasos a seguir en cuanto a la desgravación. Cierto grado de protección es necesario para mantener operando la industria con relativa normalidad, sin que esto implique permitir operar con tasas de ganancia anormales. Para ello, los aranceles a los bienes finales deben continuar siendo superiores en varios puntos a los impuestos a los insumos, si es que estos últimos no se eliminan.

Pero además, debe de dejar de considerarse que todas las ramas industriales se encuentran en las mismas condiciones de competitividad. Para poder determinar la estructura arancelaria más idónea, se deben considerar los estudios existentes sobre las condiciones de productividad y competitividad de las distintas ramas de la economía y sus tasas de protección efectiva actualmente existentes. Esto es indispensable para poder deducir al menos con mayor certeza si hay algunas ramas que gozan de sobreprotección o, por el contrario, si algunas de ellas se encuentran muy desprotegidas. Luego, se deben seleccionar aquellas que se consideren estratégicas y se deben redoblar esfuerzos para articular un programa de reconversión industrial acorde a las condiciones de 
la estructura productiva nacional.

Por último, reiteramos que algunos bienes considerados como suntuarios o de consumo restringido para ciertos sectores de la población, deberían seguir siendo tasados, permitiendo conservar esta fuente de ingresos, sin distorsionar significativamente la asignación de recursos, pues la mayoría de estos bienes no se producen internamente.

\subsection{La fijación del tipo de cambio}

Durante los últimos tres años, El Salvador ha registrado tasas de crecimiento iguales o superiores al 5 por ciento anual y la inflación tendió a bajar a partir de 1992. Las remesas enviadas por los salvadoreños residentes en el extranjero han contribuido a lograr resultados favorables en la balanza de pagos y han permitido que el Banco Central de Reserva acumule reservas internacionales en los últimos años. Este entorno favorable, propiciado por el envío de remesas y por el crecimiento de los sectores de la construcción, el comercio y los servicios, contrasta con el desempeño del sector que se supone conduciría el crecimiento dentro de la estrategia económica de largo plazo, respaldada por el gobierno y por algunos sectores empresariales. Las exportaciones no han respondido como el gobierno esperaba. Las industrias nacionales que compiten con las importaciones no han logrado limitar el crecimiento acelerado de éstas, lo cual se ha traducido en un déficit comercial creciente, reflejando así el fracaso de la estrategia adoptada en los últimos cinco años.

La política cambiara aplicada por el Banco Central de Reserva en los últimos años ha sido la flotación "administrada" del tipo de cambio - dejar que el cambio fluctúe en cierto rango, pero interviniendo con compra o venta de divisas. Esta política ha contradicho el objetivo de la política cambiaria de la estrategia económica del gobierno, propiciar un mercado de divisas flexible y libre. Como fijar el tipo de cambio equivale a intervenir en el mercado cambiario para mantener estable el tipo de cambio, los funcionarios públicos del gobierno anterior y del actual y sus asesores económicos de entonces y ahora criticaron esta práctica duramente. Para éstos, mantener fijo el valor del colón respecto al dolar, dada la inflación nacional, equivalía a subsidiar la industria nacional no competitiva y a castigar a los productores de bienes exportables y de bienes que compiten con las importaciones (es decir, los Ilamados bienes transables), incentivando el consumo por medio de las importaciones baratas y la producción de bienes no comercializables (no transables).

Ahora bien, conviene reflexionar sobre la conveniencia de esta medida y sobre la estrategia económica apoyada por el gobierno y por algunos sectores empresariales, teniendo en cuenta el entorno macroeconómico favorable, el bajo dinamismo de las exportaciones y la reforma de la política cambiaria, propuesta por sectores que hasta hace poco la consideraban perjudicial.

A nuestro juicio, fijar el tipo de cambio nominal tiene varias inconsistencias obvias. La primera está relacionada con el cambio de política propuesto en contraste con el contexto macroeconómico actual y el proyectado. Si en el país la inflación tiende a la baja, el producto ha crecido y se proyecta que continuará creciendo junto con la entrada de recursos externos. Entonces, ¿por qué se quiere fijar el tipo de cambio a un nivel artificialmente alto, aun en contra del entorno favorable?

Generalmente, la persistencia de una inflación alta obliga a medidas nominales para proteger al sector productor de bienes transables de la economía, entre ellas, la devaluación, la intervención discrecional de la banca central en el mercado cambiario, los subsidios a la exportación y la devolución de impuestos al sector exportador. Todo ello tiene como objetivo evitar una recesión o salir de ella más rápidamente. Si las reservas internacionales en poder del banco central se erosionan rápidamente, también es necesaria una depreciación o una devaluación que refleje la escasez de divisas y equilibre el sector externo. Estos son los principios teóricos generalmente aceptados.

En nuestro caso, fijar el tipo de cambio a un nivel alto estaría indicando dos aspectos negativos que contradicen las versiones oficiales sobre el desempeño y la conducción de la política económica: la inflación observada no va a bajar y, en consecuencia, se requieren medidas nominales 


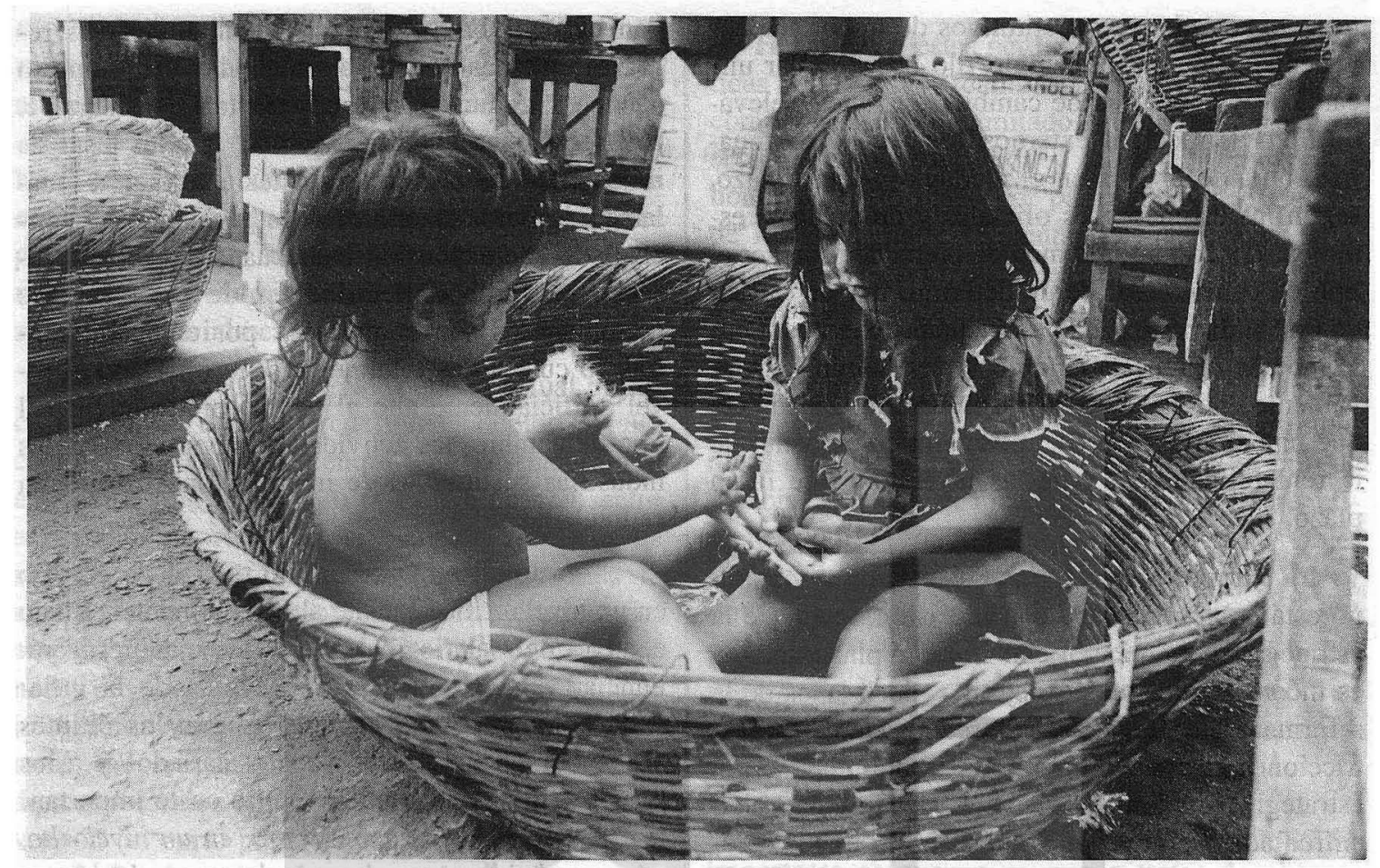

para proteger la rentabilidad real del sector transable, y el Banco Central de Reserva abandonaría su objetivo principal, esto es, el control de las presiones inflacionarias en la economía. La intervención del Banco Central de Reserva para mantener un tipo de cambio nominal fijo $y$ artificialmente alto, en contra de las tendencias económicas internas y externas, implicaría cambiar el objetivo de su política monetaria actual, regular los agregados monetarios en forma anti-inflacionaria.

Aun suponiendo que existan razones justificadas para fijar el valor de la moneda - las que hasta ahora no han sido argumentadas clara y suficientemente-, éste se pretende fijar en un nivel tal que contradice los objetivos declarados de la medida, es decir, mayor estabilidad y menor incertidumbre. Se pretende fijar el tipo de cambio en el nivel observado en los últimos dos años, asumiendo que ese nivel refleja el equilibrio del mercado cambiario. Pero es sabido que este nivel fue alto, comparado con el nivel que pudo alcanzarse si el Banco Central de Reserva no hubiese intervenido en el mercado cambiario. Incluso actualmente, si el Banco Central de Reserva no interviniese, el tipo de cambio seguiría tendiendo a bajar, presionando por una reducción mayor de la inflación nacional. Por lo tanto, aun cuando la fijación propuesta en un nivel tan alto no produzca presiones inflacionarias mayores, tal fijación evita que tales presiones se reduzcan más rápidamente, lo cual contradice el objetivo de la estabilidad de los precios de la política económica.

Adicionalmente, un tipo de cambio alto implica un nivel de salario real más bajo para los trabajadores del sector transable y no transable. Nuevamente, es conocido el hecho que ningún país ha mantenido una estabilidad macroeconómica, mucho menos social, en el largo plazo, a costa de limitar el poder adquisitivo del sector laboral productivo, sea en el sector transable o en el no transable.

La fijación propuesta desdeña un hecho macroeconómicamente inobjetable: no se puede afectar una variable real con la manipulación de otra nominal, más allá de un corto plazo y a costa de distorsiones sectoriales costosas. Es conocido el problema de "apreciación" cambiaria que los sec- 
tores exportadores y sustitutivos de importaciones resienten. El tipo de cambio fijo busca evitar una caída mayor del tipo de cambio real ante el elevado flujo de recursos externos, los cuales continuarán entrando al país en el mediano y largo plazo, según las estimaciones oficiales y de diversos estudios. Por lo tanto, la medida pretende proteger el tipo de cambio real de un deterioro mayor, causado por la disponibilidad de recursos externos. Pero la medida propuesta es de carácter nominal. Nuevamente, no ha sido demostrado empíricamente que una simple fijación impacte el crecimiento de la rentabilidad real y de las inversiones de largo plazo.

La propuesta de reforma del sistema cambiario no está contextualizada con precisión dentro de la estrategia económica ofícial de largo plazo, lo cual es inconsistente con los objetivos declarados de la reforma. Es evidente que la realidad impone restricciones al mantenimiento de la política y de la estrategia económica oficial, las cuales han sido enfrentadas con excepciones disimuladas y discrecionales en la aplicación oficial del modelo de economía de mercado, tales como la intervención en los mercados cambiario y financiero y la aplicación política de normas supuestamente técnicas. Fijar el tipo de cambio evidencia la necesidad que tiene el gobierno de rectificar su estrategia económica oficial y el rol que le pretende dar al Estado dentro de la economía. No reconocer esto, además de posponer la necesaria discusión sobre la política económica, la política social y el papel del Estado dentro de ellas, genera inestabilidad, basada en expectativas erróneas, puesto que los agentes económicos desconocen el contexto de la medida dentro de la estrategia oficial así como su carácter futuro.

Al analizar la fijación del tipo de cambio hay que evaluar sus beneficios y sus costos. Así, el beneficio potencial de una medida de este tipo es evitar la inestabilidad causada por condiciones externas adversas, pero temporales - tales como el alza de la tasa de interés internacional y, en general, la caída repentina de los términos del intercambio- y por especulaciones negativas de los agentes económicos -capitales externos volátiles no vinculados a la inversión de largo plazo. Si se dan desequilibrios nominales temporales, las reservas externas resultarían afectadas y el impacto sobre el producto real no sería tan considerable. Adicionalmente, podría esperarse que las tasas de inflación y de interés nacionales tendieran a igualarse a las tasas externas (si los problemas de déficit fiscal, de expansión inadecuada del crédito interno y de la especulación de empresarios cortoplacistas son controlados por el banco central, lo cual no es totalmente seguro). Dado el nivel artificialmente alto al que se pretende fijar el tipo de cambio, las actividades exportadoras y las industrias sustitutivas de importaciones resultarán estimuladas.

El costo para mantener fijo el tipo de cambio en un nivel artificialmente alto sería mantener bajo el nivel del salario real de los trabajadores y renunciar a una reducción más rápida de la inflación, comparada con la registrada en los últimos dos años, lo cual afecta a los asalariados y a los pensionados, principalmente. Otro costo importante es que un tipo de cambio fijo, en un nivel alto, es un subsidio para los productores de bienes transables, en perjucio de otros sectores productores de bienes no transables (tales como la construcción, los servicios y el comercio local) y de los salarios reales de los trabajadores.

Adicionalmente, la adopción simultánea de otras medidas, como el aumento del IVA o la reducción de los aranceles, profundiza o menoscaba estos costos y beneficios, dependiendo del sector analizado. Ante esto, se deben considerar varios aspectos antes de decidir la fijación del tipo de cambio. La adopción de una medida como ésta no debería soslayar el siguiente conjunto de consideraciones, las cuales deben ser evaluadas antes de implementar la reforma.

Primera, la fijación del tipo de cambio propuesta refleja la necesidad de evaluar la aplicación de la política económica, tanto desde la perspectiva de la consistencia macroeconómica, como desde la perspectiva del modelo de sociedad que se busca. En primer lugar, es claro que una estrategia que ponga énfasis a priori en el desarrollo del sector transable (principalmente exportador), no ha demostrado ser coherente con el desarrollo paralelo del sector humano productivo, mucho menos 
con el de aquellos que no pueden insertarse en el modelo de crecimiento propuesto. A partir de lo anterior, si lo que se busca con la fijación cambiaria no es privilegiar el crecimiento del sector productor de bienes transables, las autoridades económicas deben explicar claramente las razones para implementar la medida y la relación de la nueva política cambiaria con el modelo económico anunciado oficialmente.

En segundo lugar, es claro que la actual política cambiaria debe de redefinirse, debido al alto costo en que el banco central y el país incurren al apoyar un tipo de cambio favorable para el sector exportador y productor de bienes sustitutivos de importaciones. Todavía no se ha demostrado la conveniencia de ese apoyo estatal en términos del empleo generado por estos sectores, de la componente de valor agregado por su producción, de la integración vertical y horizontal con los otros sectores, del crecimiento de la componente salarial dentro del valor agregado, de la calidad de la inversión (el corto plazo versus la inversión permanente). Por lo tanto, el apoyo se ha fundamentado casi exclusivamente en consideraciones políticas más que en consideraciones de desarrollo de la infraestructura productiva y social del país.

En tercer lugar, la política monetaria asociada a la cambiaria también debe redefinirse, para evitar las pérdidas relacionadas con el pago de los intereses por emisión de bonos y la captación de reservas bancarias para regular la liquidez. Estas pérdidas no existirían si el Banco Central de Reserva no tuviera que estar comprando dólares (monetizándolos), expandiendo aceleradamente la masa monetaria e intentando contraerla, y emitiendo bonos (principalmente certificados de estabilización monetaria) que pagan un interés más alto del que ganan los activos externos que se compran con los dólares captados por dicho banco. Un efecto adicional de estas medidas monetarias es la presión para que las tasas de interés nacional se mantengan altas.
Hasta 1992, estas pérdidas asociadas a las políticas monetaria y cambiaria eran considerables, ) comparadas con el limitado presupuesto fiscal de 'sectores como educación y salud. La emisión de bonos de corto plazo por parte del Banco Central de Reserva, que está alentando inversiones especulativas de corto plazo en el limitado mercado nacional de valores, también tiene que ser evaluada como parte de la política monetaria. Se debe redefinir la función real del Banco Central de Reserva, ya que en el último quinquenio ha enfrentado el dilema de controlar la inflación y el tipo de cambio sólo con el manejo monetario. La redefinición podría proporcionar coherencia en los objetivos de la política cambiaria y monetaria. A partir de aquí también podría definirse con precisión el papel real del Estado en la promoción del crecimiento de los sectores, una vez demostrada su contribución efectiva y potencial al desarrollo de los recursos humanos y materiales.

Segunda consideración. Otro aspecto no menos importante es que no se puede tratar de obtener ganancias de competitividad de largo plazo sin logros en el área de la productividad real. El financiamiento del déficit fiscal, así como el gasto fiscal y su composición, deben modificarse, reorientándose a campos prioritarios. La modernización del sector público junto con la modernización real del sector privado deben ser estudiadas así como la complementación de la política económica con la política de desarrollo social del país. Esto último sugiere la necesidad de que el Estado revalore la conveniencia de la aplicación de un modelo económico que, de funcionar de acuerdo a los postulados teóricos, habría transformado de hecho la realidad de muchos países. La evidencia obliga a reflexionar con más realismo sobre los fracasos del modelo.

Al mismo tiempo, el sector privado, principalmente el empresarial productor de bienes transables, debe revalorar su esfuerzo para obtener

\section{El costo para mantener fijo a un nivel artificialmente alto el tipo de cambio sería mantener bajo el nivel del salario real de los trabajadores y renunciar a una reducción más rápida de la inflación.}


ganancias de competitividad real. La posible aceptación apresurada por parte de este sector de una medida que fije el tipo de cambio a un nivel artificialmente alto, sin estar acompañada por otras medidas simultáneas de carácter real, indicaría una percepción muy limitada acerca del reto para modernizar la estructura productiva y social del país. Una adopción apresurada de la reforma cambiaria propuesta, desdeñaría otros esfuerzos para aumentar la productividad real (y la competitividad) de los sectores exportador, sustituidor de importaciones y productor de bienes no transables.

De ocurrir esto último, se estaría nuevamente postergando la necesaria reconversión industrial, la capacitación técnica del sector laboral, la aplicación de políticas de desarrollo del recurso humano de amplio alcance y se continuaría dando mayor importancia a la adquisición de tecnología sin un desarrollo paralelo del factor humano, a la rentabilidad de corto plazo versus la de largo plazo, al proteccionismo altamente parcializado sin evaluar la compensación económica intersectorial versus la aplicación de una estrategia económica basada en el desarrollo paralelo de los recursos materiales y del factor humano. Los esfuerzos gubernamentales para captar recursos financieros y ponerlos a disponibilidad del sector inversionista, por medio de fondos de crédito, de garantía al crédito y otros, no se traducirán en aumento de productividad y de competitividad si el sector laboral no se desarrolla paralelamente. Así, pues, continuaríamos careciendo de un crecimiento de la inversión interna. El mismo sector empresarial debe calificar a sus cuadros gerenciales, permitiendo que sus gerentes administren dentro de una esfera profesional en lugar de "familiar". La modernización del Estado (no entendida como simple reducción del tamaño de las instituciones y la venta de los activos públicos) es elemento complementario e imprescindible para la modernización de las empresas privadas. Estos aspectos - junto a procesos de reforma económica con impacto redistributivo de carácter social progresivo- explican mucho el desempeño de países recién industrializados como Corea que, incluso enfrentados a tendencias a la baja del tipo de cambio real, aumentaron su competitividad, basada en mayores niveles de productividad y de desarrollo humano (y no en tipos de cambio nominales).

Finalmente, los argumentos antes expuestos evidencian la necesidad real de formular medidas y políticas económicas que trasciendan un modelo de economía de mercado libre, oligopólico y socialmente inaceptable, el cual ha demostrado incapacidad en generar, más allá de buenos resultados macroeconómicos, el desarrollo de grandes segmentos de la población.

\subsection{La privatización y las mayorías populares}

La privatización es la cuarta medida del conjunto de la propuesta. Cabe decir, por supuesto, que la privatización no es un fenómeno exclusivo de nuestro país, sino una tendencia mundial. Por ello importa tratar de establecer algunos aspectos.

En primer lugar, ¿cómo se explica la privatización? A nuestro juicio, se trata de una medida cuya finalidad última es ampliar los espacios de valorización del capital, es decir, ampliar el ámbito de actividad en el cual el capital puede obtener mayores beneficios. Al igual que las otras medidas, como la apertura comercial, el incremento del IVA, la fijación del tipo de cambio del colón a un nivel muy alto y el alza de las tarifas de los servicios públicos, la privatización traerá como consecuencia lógica la disminución del poder adquisitivo de todos aquellos que tenemos ingresos fijos $y$, en definitiva, provocará mayor empobrecimiento de la fuerza de trabajo.

La privatización esconde una realidad: existe una crisis de valorización. Por eso mismo se busca refuncionalizar el capital a nivel mundial. Nuestra economía no es ajena a esta dinámica, debido a nuestra excesiva dependencia económica y política. De lo contrario, cómo entender que el gobierno haya anunciado en el extranjero que el capital internacional puede adquirir activos tales como la zona franca San Bartolo, el complejo industrial pesquero Punta Gorda, los ingenios azucareros, la textilera INSINCA y la generación y distribución de energía eléctrica, esto es, CEL, CAES, CLESS, CLESA, CLEA y DISCEL, sin que existan decretos legislativos que autoricen tales enajenaciones.

Por otra parte, después de la reprivatización de la banca y de la exagerada concentración y centra-

ESTUDIOS CENTROAMERICANOS (ECA) 555-556 
lización del capital generado, los empresarios nacionales se han entusiasmado con el proceso privatizador y claman para que se acelere, ya que vislumbran excelentes "oportunidades" para incrementar sus fortunas, gracias a la forma "generosa" y nada transparente como se está llevando a cabo el proceso de privatización. Todo ello es muy lamentable, ya que no se han buscado alternativas racionales, adecuadas y justas a los intereses nacionales, esto es, a los intereses de la mayoría de la población, la cual, lejos de resultar beneficiada con la ola privatizadora, se verá seriamente afectada por tales medidas en el corto y mediano plazo y lejos de encaminarnos hacia la estabilidad social, lo que se está generando es una mayor exclusión social que, seguramente, se manifestará ęn una inestabilidad política seria.

En segundo lugar, ¿cómo se pretende justificar la privatización? Se acude a argumentos tales como que el Estado no tiene nada que hacer en actividades que son propias de la sociedad civil o del sector privado. Olvidando cómo y por qué se llegó a tal situación. Los que apoyan actualmente la privatización ya olvidaron que fue, precisamente, ante la crisis capitalista de los años treinta que se impuso la teoría keynesiana, que postulaba la intervención del Estado en la economía para sacar al capitalismo de la crisis. Ahora, en cambio, se hace responsable de la crisis a la intervención del Estado en la economía, lo cual no deja de ser paradógico.

También se habla de la ineficiencia per se del Estado. ¿Cómo explicar entonces las millonarias utilidades de ANTEL e insistir tozudamente en su privatización? Un análisis más serio permitiría observar que los profesionales y los técnicos que trabajan en empresas públicas o privadas se intercambian, por lo tanto, el problema de la ineficiencia que presentan las empresas e instituciones públicas no es de carácter técnico, sino más bien político, ya que al frente de ellas se pone a personas incapaces $\mathrm{y}$, o corruptas que las terminan desfalcando o quebrando. CEL, por ejemplo, fue una empresa modelo de eficiencia hasta de que al frente de ella se pusieron militares "retirados". Tampoco es cierto que las empresas privadas sean una maravilla de eficiencia, de ser así, no se entendería que tantas empresas industriales quiebren ante la apertura comercial. La empresa privada capitalista no es todo lo eficiente que pretende ser. Ello se evidencia en el hecho de que cada año, cientos de miles de empresas capitalistas quiebran a nivel mundial.

También se pretende justificar la privatización apelando al déficit fiscal. Si ésa fuese la razón verdadera, sería una solución verdadera o, en todo caso, mucho más efectiva, privatizar o mejor aún, eliminar el Ministerio de Defensa, ya que, al fin y al cabo, es la cosa más inútil e innecesaria que existe en el país. Si se suprimiera, pronto tendería a desaparecer el déficit fiscal. Se podría comenzar privatizando el Instituto de Previsión Social de la Fuerza Armada (IPSFA), la cooperativa y el hospital militar, hasta llegar a la institución militar misma. Y no se piense que no estamos hablando seriamente, ya que el apóstol del neoliberalismo, Milton Friedman, sostiene que debería de privatizarse la emisión monetaria, la seguridad pública, etc. De justificarse el argumento del déficit fiscal, existe también la posibilidad de buscar otras alternativas menos radicales, por ejemplo, evitar la evasión tributaria haría innecesario incrementar la tasa del IVA, cerrar el déficit fiscal y evitar la privatización de los servicios públicos.

¿Pero cómo se puede justificar la privatización de empresas o de activos públicos que no son una carga fiscal, sino que, por el contrario, generan o podrían generar ingresos al gobierno tales como la zona franca San Bartolo, ANTEL, la generación y distribución de energía eléctrica, los beneficios de café y los ingenios azucareros, los complejos pesqueros, etc.? ¿Por qué no pensar en arrendar en vez de vender? ¿Qué sentido tiene, por ejemplo, privatizar INSINCA si es una empresa eficiente y en la cual el Estado sólo tiene el 50 por ciento de las acciones? ¿Acaso no sería más práctico redefinir el destino de esas utilidades?

En tercer lugar, ¿qué podemos y debemos hacer? Tomemos en cuenta que las empresas e instituciones que se busca privatizar no son propiedad del gobierno, sino que pertenecen al Estado y que éste lo integramos todos. En consecuencia, es preciso que la privatización beneficie a la mayoría de los salvadoreños y no sólo a unos cuantos. 
Adicionalmente, postulamos que los servicios básicos mínimos no mercantiles que ya se prestan de manera gratuita no deben de ser privatizables, por ejemplo, salud, educación; tampoco deben privatizarse servicios vitales tales como agua y electricidad.

Finalmente, deberían considerarse algunas características para que la privatización beneficie a las mayorías. En primer lugar, las empresas y, o instituciones que se consideran privatizables debieran tener tres destinatarios: primern, los empresarios capitalistas, estableciendo un porcentaje máximo, de acuerdo al valor de cada empresa y, o institución. El pago debería efectuarse al contado. Segundo, los trabajadores de las empresas y, o instituciones, cooperativas y asociaciones de micro y pequeños empresarios, vinculados a las empresas $\mathrm{y}$, o instituciones, con un procentaje máximo a determinar, de acuerdo al valor de cada empresa y, o institución. El pago se haría al crédito y se amortizaría con los beneficios obtenidos, sin tener que pagar intereses. Tercero, el Estado, el cual se reservaría la propiedad de lo no vendido de cada empresa y, o institución, pero que los beneficios los destinaría a salud y educación. Previamente habría que determinar qué porcentaje de los beneficios de cada empresa y, o institución privatizada se destinaría a salud y a educación. Por ejemplo, de las utilidades que le correspondería a la propiedad estatal de ANTEL, un determinado porcentaje se destinaría a la Universidad de El Salvador, al INFRAMEN, al Hospital Rosales, al Hospital Bloom, etc., estableciendo a su vez que estos fondos deben ser utilizados en gastos de funcionamiento e inversión, quedando excluidos los sueldos, los salarios y los honorarios, los cuales deberían ser siempre cubiertos por el Estado.

En segundo lugar, es conveniente que las nuevas empresas que surjan de la privatización adquieran la modalidad de sociedades cooperativas - una forma híbrida reconocida por el Código Mercantil, que retoma lo bueno de las sociedades anónimas y de las asociaciones cooperativas, sin confundirse con ninguna de las dos-, con lo cual habría cierta garantía de que lo logrado con la propuesta anterior fuese permanente, es decir, que perdurara en el tiempo y, al mismo tiempo, evita- ría la concentración del capital en unas pocas manos.

En tercer lugar, los ingresos obtenidos o por obtenerse de las ventas al contado o al crédito en lugar de que se diluyan en las arcas nacionales- debieran destinarse a financiar un programa de vivienda popular en las áreas urbana y rural, con bajos intereses y según el sistema de ayuda mutua, creando un fondo rotativo que fuera cubriendo progresivamente a más familias carentes de una vivienda digna.

En cuarto lugar, las empresas de propiedad mixta no deben ser objeto de privatización, sino que tan sólo se debe definir el destino de los beneficios obtenidos, conforme a lo señalado en la primera propuesta.

En quinto lugar, los activos que puedan ser arrendados, no debieran ser vendidos. Los ingresos generados por el arrendamiento deben ser destinados a las áreas de salud y educación. Esto indicaría una mentalidad prudente, ya que de esa manera se estaría evitando cometer errores de carácter irreversible y de los cuales nos lamentaríamos en el futuro. Actuar apresuradamente es propio de los irresponsables y, o de los deshonestos, de allí que la administración de Calderón Sol, si no actúa con sabiduría y prudencia, pasará a la historia como el gobiemo que dejó en la calle a la mayoría de los salvadoreños, triste herencia para el segundo gobierno de ARENA.

En consecuencia, si la privatización se lleva cabo en los términos planteados, ciertamente, no evitará la ampliación de la órbita o de los espacios de valorización del capital, pero al menos habría una democratización de la propiedad y las mayorías populares resultarían beneficiadas, al inyectar recursos a las áreas sociales, sin recargar el presupuesto nacional.

Finalmente, el gobierno debe informar públicamente qué activos se han privatizado, quiénes los han adquirido y bajo qué condiciones se han vendido. Asimismo, debe hacer público cuál ha sido el destino de los recursos obtenidos. Esta información debe cubrir la administración anterior y la actual. Por otra parte, también debe informar qué activos tiene programado privatizar, de tal manera 
que la sociedad civil pueda opinar, hacer consideraciones y plantear alternativas racionales a las intenciones del gobierno.

\section{Conclusiones y propuestas}

Las nuevas medidas parecen sugerir la implantación de un nuevo modelo económico, cuyo objetivo final sería reconvertir El Salvador en una colonia o provincia dependiente del mercado internacional. Ya se ha hablado de convertir el país en una gran zona franca. La maquila no puede constituirse en un pilar de desarrollo de largo plazo país por diversas razones, entre ellas, porque el empleo que genera es temporal, por las remuneraciones bajas, porque no garantiza los derechos legalmente reconocidos de los trabajadores, por las limitaciones para cualificar al trabajador, por el acelerado desgaste de la capacidad productiva del trabajador, pero fundamentalmente por su desarticulación del resto de los sectores de la economía nacional.

El entorno global de las medidas se caracteriza por la presencia de gran pobreza, el crecimiento sin empleo y la atomización e insolidaridad social. Todo ello unido a la baja productividad y competitividad de los sectores económicos que temen la apertura internacional, la falta de inversión, la falta de integración económica interna en razón de la estructura oligoexportadora tradicional, la notoria ausencia de cualificación profesional de la mano de obra, la corrupción generalizada, la delincuencia callejera, el narcotráfico, el lavado de dólares, el carro-tráfico, el crimen civil o político, el tráfico de influencias, la aun deficiente administración de justicia, el ocultamiento de la verdad, tantas inseguridades sociales, el miedo, la inseguridad en la que todos vivimos así como la falta de solidaridad social de postguerra manifiesta en el resquebrajamiento de los partidos políticos, todo ello, frena la inversión nacional y levanta los aranceles mayores a la inversión extranjera.

La contradictoria realidad que enfrenta el modelo es que las tarifas y los precios se incrementan, pero no así la productividad requerida en muchas de las ramas del sector productivo. Esto demuestra que la economía general no está capacitada para una pronta aplicación de estas medidas económicas, por lo tanto, se requiere un tiempo de espera. Para abrirse hacia fuera, nuestra economía necesita una mayor integración, diversificación y modernización internas. Lo último que necesitamos son medidas económicas que las dificulten. La situación del agro es grave. Por eso, una medida tan aventurada como una apertura comercial total podría ser un atentado para la estabilidad social y política, la cual es un prerrequisito para cualquier estrategia de desarrollo sostenible.

El incremento del IVA favorecería al Ministerio de Hacienda y a las empresas que lo cobran y no lo pagan, pero castigaría sobradamente a la mayoría de la población. Con esta medida sólo se acentuaria la regresividad del sistema tributario, con lo cual no se asegura un estímulo importante al ahorro interno. El incremento es indeseable desde una perspectiva de equidad económica y social. Justificar un mayor IVA como pago por la paz alcanzada es una carga para la mayoría de la población, ya que fueron los consumidores asalariados y de bajos ingresos los más perjudicados con la reforma tributaria. Los costos de la guerra fueron pagados con vidas e ingresos principalmente provenientes de esos sectores. Si alguien se benefició de la guerra, no fue el sector de bajos ingresos. Consecuentemente, el intento para justificar el alza del IVA lo único que evidencia es la enorme desarticulación entre el manejo de la política fiscal y la implementación de una política social consistente por parte del parte del gobierno.

El déficit fiscal, producto de la evasión, de la corrupción, de la ineficiencia administrativa del Ministerio de Hacienda y de las empresas públicas, debiera ser corregido con medidas serias para abordar estos problemas. Esto incluye un examen de la racionalidad económica del Banco Central de Reserva, el cual ha estado enfrentado al dilema de su políticas monetaria y cambiaria. Por lo demás, es obvia la indeseabilidad económico financiera de cerrar un déficit global vía un mayor ahorro público a costa de un menor consumo y ahorro privado.

La reducción y eliminación de los aranceles favorecería momentáneamente a algunas ramas productivas, mientras que expulsaría de la escena económica a otros sectores importantes. La penetración de nuevos mercados no depende de una apertura unilateral de nuestra economía, sino más 


\section{Económica y socialmente es mucho más deseable y recomendable aumentar la eficiencia administrativa del Ministerio de Hacienda en lugar de aumentar la tasa el IVA.}

bien de incrementos de competitividad real interna y de aspectos complementarios importantes. La aceptación de un arancel cero implicaría admitir que todas las ramas industriales se encuentran en condiciones para competir en el exterior o que la "mano invisible" de la economía se encargará de decir las que merecen sobrevivir y las que no. También significaría que las negociaciones de los acuerdos de libre comercio y las negociaciones sobre los aranceles, en el marco de la integración centroamericana, carecen de sentido en la parte de desgravación arancelaria. Si éste fuera el caso no estaríamos desviando de la tendencia actual, encabezada por las grandes potencias, para formar bloques económicos. Si bien las negociaciones en torno a temas como las barreras no arancelarias, los servicios, la inversión, las medidas de salvaguardia, la competencia desleal y otras medidas, podrían continuar, mucho del reducido poder de negociación que tenemos ante los países económicamente más fuertes, se perdería.

La fijación del tipo de cambio equivale a legitimar la intervención del Banco Central de Reserva en el mercado cambiario para mantenerlo estable. La fijación en un nivel artificialmente alto va en contra de las tendencias económicas internas y externas, e implicaría un cambio de objetivo de la política monetaria del Banco Central de Reserva. Significa que éste perseguiría mantener el tipo de cambio fijo en lugar de regular los agregados monetarios en forma anti-inflacionaria.

Fijar el tipo de cambio evidencia la necesidad que tiene el gobierno de rectificar su estrategia económica oficial y el rol que le pretende dar al Estado dentro de la economía. No reconocer esto, además de posponer la necesaria discusión sobre la política económica, la política social y el rol del Estado dentro de ellas, genera inestabilidad, basada en expectativas erróneas, puesto que los agentes económicos desconocen el contexto de la medida dentro de la estrategia oficial así como su futuro.
El costo para mantener fijo a un nivel artificialmente alto el tipo de cambio sería mantener bajo el nivel del salario real de los trabajadores y renunciar a una reducción más rápida de la inflación. Un tipo de cambio fijo, en un nivel alto, es un subsidio para los productores de bienes transables, especialmente para el sector exportador, en perjucio de otros sectores como la construcción, los servicios y el comercio local. El impacto severo lo padecerian los salarios reales de los trabajadores. La estrategia que a priori enfatiza el desarrollo del sector exportador, no ha demostrado ser coherente con el desarrollo paralelo del sector humano productivo, mucho menos con el de aquellos que no pueden insertarse en el modelo de crecimiento propuesto.

El gobierno está más interesado en privatizar los activos del sector público que en privatizar los activos concentrados del sector privado $y$, claro está, determinadas privatizaciones beneficiarán lucrativamente a determinadas empresas y a ciertos consumidores, pero generarán la angustia del desempleo en amplios sectores laborales. Este mercado tan heterogéneo y falto de poderes compensadores no puede, por sí sólo, ser el eje orientador del quehacer económico.

La mayoría de la población presiente, no sin razón, que la aplicación de las nuevas medidas económicas la impactará perversamente, pues sobre ella pesarán las nuevas tarifas de luz, agua, teléfono, sumadas a las amenazas del incremento del IVA y del desempleo derivado de los imprecisos proyectos de privatización.

El modelo económico no sólo debe ser evaluado por el crecimiento conservador del PIB, porque estos crecimientos globales no significan todavía ni crecimientos armónicos, ni crecimientos con equidad. Por ello, hay que recurrir a otros criterios como los siguientes para evaluar dicho modelo: el impacto sobre la calidad del empleo generado, la satisfacción de las necesidades esenciales para la mayoría de salvadoreños, el nivel de integración 
del aparato productivo nacional, la promoción de las exportaciones articuladas al resto del aparato productivo cuya competitividad descanse fundamentalmente en incrementos de la productividad, tanto del recurso humano como del capital físico, y la sustitución de importaciones claves para el funcionamiento del aparato productivo nacional. Los criterios anteriores deberían inspirar el plan de desarrollo y el quehacer del sector público y privado.

El gobierno resiente la crítica y solicita propuestas. Esto no deja de de ser una pretensión en tanto no tiene un plan de desarrollo y tampoco se dispone de suficiente información transparente como para hacer propuestas técnicas. De todas maneras, no queremos terminar, sin presentar algunas propuestas.

Económica y socialmente es mucho más deseable y recomendable aumentar la eficiencıa administrativa del Ministerio de Hacienda en lugar de aumentar la tasa el IVA, eliminar la evasión y las prácticas de corrupción implícitas, eliminar la devolución de impuestos al café y mejorar la gestión en las empresas públicas.

Los aumentos en las tarifas públicas deben estar precedidos por un análisis exhaustivo del costo marginal "real" de largo plazo que se pretende cubrir, para verificar la efectividad real del costo. Recuérdese que esas empresas públicas continúan teniendo déficits, a pesar del aumento de sus ingresos debido al incremento de las tarifas. Esos déficits son el resultado de la ineficiencia gerencial, causada por el manejo político a que históricamente han sido sometidas. Una medida de este tipo es más difícil pero, seguramente, el déficit real que debe ser financiado debería reducirse con una política gubernamental de autodepuración financiero administrativa.

El financiamiento del déficit fiscal, así como el gasto fiscal y su composición deben modificarse, reorientándose a campos prioritarios. La modernización del sector público junto a muestras reales de modernización en el sector privado, deben de estudiarse, así como la complementación de la política económica con la política de desarrollo social del país. Esto último sugiere la necesidad de que el Estado revalore la conveniencia de la aplicación de un modelo económico que, de funcionar de acuerdo a los postulados teóricos, habría, de hecho, transformado la realidad de muchos países. La evidencia obliga a reflexionar con más realismo sobre los fracasos del modelo.

La reducción de los aranceles para los insumos, los bienes intermedios y la maquinaria significará una disminución de los costos de producción de los empresarios, pero no debemos olvidar que si algunos bienes considerados como insumos para algunas empresas son a la vez producidos internamente, como el caso del papel, la reducción de los aranceles debilitará una parte del aparato industrial, $y$, en ese sentido, debemos ver el costo contra la ganancia generada por la reducción de los costos de producción de la mayoría de las empresas.

Debería otorgarse una protección sectorial selectiva para las industrias con potencial para expandirse y exportar, sin que esto signifique elevar las tarifas arancelarias. Una política sectorial para la industria debería incluir planes de modernización, mejora de infraestructura, suministro de servicios básicos, incorporación de nueva tecnología, adiestramiento de personal y centros de información de oportunidades en el exterior.

Consideramos que cierto grado de protección es necesario para mantener operando con relativa normalidad la industria, sin que esto implique permitir operar con tasas de ganancia anormales. Para ello, los aranceles a los bienes finales deben continuar siendo superiores en varios puntos a los impuestos sobre los insumos. Y además, los bienes de consumo suntuario podrían continuar siendo gravados.

Debe redefinirse la política cambiaria actual, debido al alto costo que genera para el Banco Central de Reserva y para el país apoyar un tipo de cambio en favor del sector exportador y del sector productor de bienes sustitutivos de importaciones. No ha sido demostrada la conveniencia de ese apoyo estatal, en términos del empleo que generan esos sectores, de la componente de valor agregado dentro de su producción, de la integración vertical y horizontal con los otros sectores, 
del crecimiento de la componente salarial dentro del valor agregado y de la calidad de la inversión. Pór lo tanto, el apoyo ha estado basado en buena medida en consideraciones políticas, más que en consideraciones de desarrollo de la infraestructura productiva y social del país. La política monetaria asociada a la cambiaria también debe redefinirse, para evitar pérdidas asociadas al pago de los intereses por emisión de bonos y captación de reservas bancarias para regular la liquidez.

Deberán hacerse esfuerzos por obtener ganancias de competitividad real de largo plazo como resultado de los avances en el área de productividad real. Es necesaria la reconversión industrial, la capacitación técnica del sector laboral, la aplicación de políticas de desarrollo del recurso humano de amplio alcance, la adquisición de tecnología paralela al desarrollo del factor humano e incenti- var la rentabilidad de largo plazo.

Si la privatización se llevase a cabo de acuerdo con estos criterios, habría una democratización real de la propiedad y las mayorías serían beneficiadas al inyectar recursos en las áreas sociales sin recargar el presupuesto nacional.

Queremos concluir este trabajo con una reflexión. Un país, golpeado humana y tecnológicamente por la guerra, económica y socialmente por la pobreza y la discriminación, y políticamente por la corrupción, no puede ni debe aventurarse en modelos que simplemente priorizan variables macroeconómicas. Por ello, recomendamos al gobierno así como a todos nosotros, actores del sector privado, que nos inspiremos hoy y mañana en el lema "las sociedades prósperas son las que existen en función del ser humano". 